University of Nebraska - Lincoln

DigitalCommons@University of Nebraska - Lincoln

$5-25-2021$

Component Causes of Infectious Bovine

Keratoconjunctivitis-Non-Moraxella Organisms in the Epidemiology of Infectious Bovine Keratoconjunctivitis

John Dustin Loy

Kristin A. Clothier

Gabriele Maier

Follow this and additional works at: https://digitalcommons.unl.edu/vetscipapers

Part of the Biochemistry, Biophysics, and Structural Biology Commons, Cell and Developmental Biology Commons, Immunology and Infectious Disease Commons, Medical Sciences Commons, Veterinary Microbiology and Immunobiology Commons, and the Veterinary Pathology and Pathobiology Commons

This Article is brought to you for free and open access by the Veterinary and Biomedical Sciences, Department of at DigitalCommons@University of Nebraska - Lincoln. It has been accepted for inclusion in Papers in Veterinary and Biomedical Science by an authorized administrator of DigitalCommons@University of Nebraska - Lincoln. 


\title{
Component Causes of Infectious Bovine Keratoconjunctivitis-Non-Moraxella Organisms in the Epidemiology of Infectious Bovine Keratoconjunctivitis
}

\author{
John Dustin Loy, ${ }^{1}$ DVM, PhD; Kristin A. Clothier, ${ }^{2}$ DVM, PhD; \\ \& Gabriele Maier, ${ }^{3}$ DVM, MPVM, PhD, DACVPM
}

1 Nebraska Veterinary Diagnostic Center, School of Veterinary Medicine and Biomedical Sciences, University of Nebraska-Lincoln, Lincoln, NE, USA

2 Department of Pathology, Microbiology, and Immunology, California Animal Health and Food Safety Laboratory System, School of Veterinary Medicine, University of California Davis, 620 W. Health Sciences Drive, Davis, CA 95616, USA

3 Department of Population Health \& Reproduction, School of Veterinary Medicine, University of California Davis, 1 Shields Avenue, VM3B, Davis, CA 95616, USA

Corresponding author - J. D. Loy, 4040 East Campus Loop N. 115Q NVDC, Lincoln, NE 68583-0907; email jdloy@unl.edu

\section{Key Points}

- Non-Moraxella organisms are associated with infectious bovine keratoconjunctivitis (IBK).

- Mycoplasma bovoculi can cause conjunctivitis and has a potential role in IBK pathogenesis.

- Other Non-Mycoplasma agents can cause disease that resembles IBK but is clinically different.

- Genomics and molecular technology are advancing research in this area.

- Classification and determination of pathogenesis potential of these organisms may be better understood through metagenomics and whole genome sequencing.

Keywords: IBK, Pink eye, Infectious bovine keratoconjunctivitis, Mycoplasma bovoculi, Ureaplasma, Bovine herpesvirus, Listeria, Chlamydia

Published in Veterinary Clinics of North America: Food Animal Practice 37:2 (July 2021), pp 295-308.

doi: 10.1016/j.cvfa.2021.03.005

Copyright (C) 2021 Elsevier Inc. Used by permission.

Published May 25, 2021. 


\section{Introduction}

Historically the role of bacterial organisms associated with infectious bovine keratoconjunctivitis (IBK) has fallen to members of the genus Moraxella (see John Dustin Loy and colleagues' article, "Component causes of IBK - The Role of Moraxella spp. in the epidemiology of Infectious Bovine Keratoconjunctivitis," Veterinary Clinics of North America: Food Animal Practice, 37:2, July 2021, pp 279-293; doi:10.1016/j. cvfa.2021.03.004). However, there are numerous other pathogens that have been described in association with either outbreaks or clinical cases of IBK with and without an association with Moraxella. The most significant of these include members of the genus Mycoplasma, specifically Mycoplasma bovis and Mycoplasma bovoculi, which have long been found associated with ocular infections in cattle. Other less understood potential pathogens include intracellular organisms such as Chlamydia spp. Viral causes such as bovine herpesvirus have also been associated with IBK. Other ocular diseases, including those caused by Listeria monocytogenes, may often have some clinical overlap with IBK-like diseases. Although none of these agents has strong support as a direct cause of IBK, there is evidence that infections with some may predispose animals to IBK. The role of these agents in association with IBK or IBK-like disease is reviewed later, including virulence factors, studies on causality, immune responses, and im-

portantly detection and interpretation of diagnostic findings of these organisms in IBK cases.

\section{Mycoplasma}

Members of the genus Mycoplasma are small pleomorphic bacteria that lack a cell wall, are nutritionally fastidious, have a limited metabolism, and are composed of 124 species. ${ }^{1}$ Most of the well-studied members of the genus are human or animal pathogens; however, about half of these exist as commensals or opportunistic pathogens that colonize fish, reptiles, and birds in addition to mammals. ${ }^{1}$ There are at least 13 members of the genus Mycoplasma that infect cattle, and these include those that cause respiratory, reproductive, 
mastitis, systemic diseases, and ocular infections. ${ }^{2}$ Mycoplasma is one of the most abundant genera present in the bovine upper respiratory tract. ${ }^{3-5}$ Evaluations of microbiota from calves with and without disease indicated that animals with otitis and pneumonia have a greater abundance of Mycoplasma sp than those without; and all conditions had a greater Mycoplasma sp abundance than healthy cohorts. ${ }^{6}$ Mycoplasma has been studied by using $16 \mathrm{~S}$ ribosomal sequencing to look at microbial communities within the bovine eye. Among, the top 10 genera identified, Mycoplasma showed a higher mean relative abundance in the non-IBK controls (26.86\%) compared with the IBK cases (18.29\%). ${ }^{7}$ An in vitro co-culture study conducted with human sinus epithelial cells and donor respiratory microbiota determined that the inclusion of $\mathrm{TH}-1$ macrophages shifted the microbial abundance from Corynebacterium spp, Staphylococcus spp, and Dolosigranulum spp to an abundance of Moraxella spp and Mycoplasma spp, providing some insight into how mammalian host immune status may alter microbial composition. ${ }^{8}$ Another recently published study evaluated the ocular microbiome in calves over time and showed that Mycoplasma spp were detected at all time points with variation in abundance over the preweaning period. Significant differences were also observed in microbial communities before and after clinical IBK disease, with both Mycoplasmataceae and Moraxellaceae families increasing post-IBK infection ${ }^{9}$; this indicates that Mycoplasmas are likely part of the ocular flora and may change over time and in response to IBK. The nutritionally fastidious nature of Mycoplasmas makes isolation and study in the laboratory challenging. Recovered isolates require additional characterization to identify the species isolated, which often is only performed in reference laboratories. However, with the advent of molecular techniques such as polymerase chain reaction (PCR) and gene sequencing, more tools are now available to aid researchers and veterinarians in the study and diagnosis of these infections, and future research using these techniques may establish more definitive roles for these agents in association with IBK. The lack of available tools such as vaccines and effective treatments has also impeded successful mitigation of the disease-causing Mycoplasma spp in animals, including cattle, and these areas deserve additional research attention. ${ }^{10}$ 


\section{Mycoplasma bovoculi}

$M$ bovoculi was first described following an outbreak of IBK that yielded an isolate that was biochemically different from previously described Mycoplasmas. ${ }^{11,12} \mathrm{M}$ bovoculi has a specific requirement for sterol in the culture media; use of standard Mycoplasma media may not support recovery of this agent and cause false-negative results. ${ }^{11}$

Subsequent studies on microbial flora of cattle eyes have shown $M$ bovoculi to be highly prevalent in normal calves, and asymptomatic infections can occur at an early age, with spread to other animals occurring over time, including over the winter months when vectors are at lower levels. ${ }^{13}$ The average prevalence of $M$ bovoculi in repeated samplings in this study was more than $45 \%$, which, given the challenges in isolating this organism, may indicate a much higher true prevalence. Given the apparent high prevalence in cattle eyes, it is difficult to evaluate $M$ bovoculi's contribution as a risk factor to IBK. It seems likely that $M$ bovoculi, if a pathogen, is an opportunistic one that may contribute to disease instead of directly causing IBK. Some studies summarized later show mild or absent disease when $M$ bovoculi is found alone but describe potentiation of disease when administered or found with other pathogens, such as Moraxella bovis. There may be synergism between Mycoplasma and Moraxella species; however, the exact mechanisms of such a process have not yet been described.

\section{Virulence Factors}

Virulence factors and other characteristics of $M$ bovoculi remain poorly understood. M bovoculi adheres to bovine epithelium in the absence of any specialized attachment structure and does not possess a capsule. ${ }^{14}$ The adherence is tight and primarily to bovine conjunctival epithelial cells; organisms can be observed in infected animals when stained with specific florescent antibody. ${ }^{15}$ Whole genome sequencing has been performed on the type strain of $M$ bovoculi, which is the descendant of the original isolates used in the bacterial species description and which contains a 760,240 bp genome, 626 genes, and has 7 gene pairs potentially associated with adherence factors. ${ }^{16} \mathrm{~A}$ novel contingency locus, that is, a region of hypermutable DNA, was 

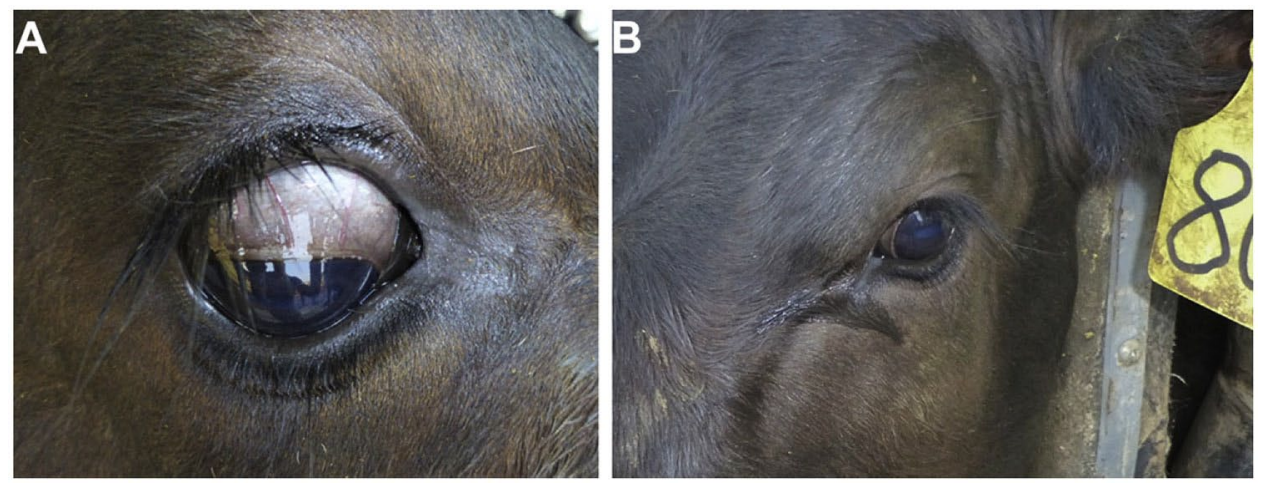

Fig. 1. (A and B) Calf with bilateral ocular discharge and mild conjunctivitis. $P C R$ detected the presence of Mycoplasma spp in the absence of other agents. (Courtesy of Dr John Angelos, UC Davis.)

also identified, which has an array of 5 genes that indicate phase variation and combinatorial expression patterns, which may be involved in host immune evasion or other host adaptations of $M$ bovoculi outer membrane proteins. ${ }^{17}$

\section{Clinical Disease}

Clinically, cattle with $M$ bovoculi-associated signs do not appear ill, but $10 \%$ to $90 \%$ may have a unilateral or bilateral ocular discharge and conjunctival hyperemia (Fig. 1). ${ }^{18}$ Field investigations of "epizootic conjunctivitis," a disease entity considered clinically different from classic IBK, isolated primarily $M$ bovoculi in 11 out of 19 lowa farms from affected animals. ${ }^{15}$ In a different study ocular samples from 6 herds with cattle showing signs of conjunctivitis yielded recovery of $M$ bovoculi from $50 \%$ to $100 \%$ of cattle but no recovery from two herds without signs of conjunctivitis. ${ }^{18}$ Experimental infection studies with $M$ bovoculi inoculation report mild conjunctivitis, and some have shown infections with $M$ bovoculi may predispose animals to Moraxella-induced IBK. For example, under experimental inoculation, calves exposed to $M$ bovoculi $(n=6)$ and Ureaplasma spp $(n=6)$ developed conjunctivitis and lacrimation 3 to 4 days following challenge and were recovered 1 to 2 months after infection. ${ }^{18} \mathrm{M}$ bovoculi was able to be re-isolated from the bovine eye following co-challenge with $M$ bovis. ${ }^{19}$ Another study describes a potential enhancement effect of $M$ bovoculi on $M$ bovis challenge in colostrum-deprived calves, where those that received $M$ 
bovoculi before $M$ bovis challenge, 4/5 eyes developed conjunctivitis within 3 days versus only $1 / 3$ that did not receive $M$ bovoculi inoculation developing conjunctivitis. ${ }^{20}$ However, the study lacked robust controls to evaluate the validity of this observed enhancement. Calves infected with $M$ bovoculi in one study had longer colonization times and developed keratitis at higher rates when challenged with $M$ bovis ( $n=6 / 6$ calves) when compared with those without mycoplasma exposure (0/4 calves). ${ }^{21} \mathrm{M}$ bovoculi also seemed to increase colonization levels of Moraxella ovis in calves. One study showed $0 / 3$ calves had $M$ ovis isolated from eyes 15 days after inoculation when compared with those that had been inoculated with $M$ bovoculi before $M$ ovis ( $3 / 3$ calves). There were also significant differences in colony forming units/swab of $M$ ovis isolated between these 2 treatment groups at earlier time points. ${ }^{22}$ Even though several studies point toward a possible role of Mycoplasma in IBK, extrapolation of results from small experimental studies, which often lack blinding and randomization of study animals, requires confirmation of findings in field trials. Difficulty arises from the fact that prevalence of $M$ bovoculi infection in eyes of cattle populations seems to be very high, which may actually obscure its potential role as a risk factor.

\section{Immunity}

Immune responses to $M$ bovoculi seem robust in recovered animals and include immunoglobulin A $(\lg A)$ in lacrimal and nasal secretions in addition to serum $\lg G$ and $\lg M$ and cellular immune responses. ${ }^{23,24}$ Previous natural exposure to these organisms seems to provide protection against colonization. One study showed that in calves with evidence of prior $M$ bovoculi colonization that were vaccinated and subsequently challenged, most cleared the organism by day 3 and all were negative by day 10 postchallenge. None of these animals showed evidence of conjunctivitis. In contrast, protection from $M$ bovoculi challenge in gnotobiotic calves was not induced by administration of killed $M$ bovoculi antigens (either from membrane extracts or killed whole organism); all animals developed conjunctivitis and had $M$ bovoculi recovered throughout the study period (15 days). ${ }^{24} M$ bovoculi strains have similar, but not identical, protein profiles, with antigenic differences apparent when evaluated by immunoblotting 
with serum from recovered calves. However, a 94 kDa outer membrane protein that seems antigenically identical across multiple strains and monoclonal antibodies raised against this protein interact with other Mycoplasma species. ${ }^{25,26}$ Ocular challenge with $M$ bovoculi seems to result in enhanced systemic natural killer (NK) cell activity as well as to induce NK migration into bovine eyes following acute infection. ${ }^{27}$ A small study with 65 cattle from India found serum IgG antibodies that reacted to sonicated $M$ bovoculi antigens in $44 \%$ of cattle with IBK and $15 \%$ of nonclinical cattle, indicating an association between immune response and clinical disease. ${ }^{28}$

\section{Epidemiologic Studies}

Some associations between the presence of $M$ bovoculi and IBK have been found, but the evidence has to be interpreted with caution. Schnee and colleagues (2014) examined the point prevalence of IBKassociated pathogens in cattle from 4 different herds in Europe representing 4 different clinical stages of IBK. The investigators found that herds early in the course of IBK had a higher prevalence of $M$ bovoculi detected by PCR than those recovering from or without clinical IBK and hypothesized that herds with higher $M$ bovoculi prevalence are predisposed to acute outbreaks of IBK, possibly due to synergism with Moraxella spp. However, further studies are needed to confirm the findings of the cross-sectional study that may have been confounded by different breeds, housing types, or other management factors. ${ }^{29}$ Other surveys indicate that the prevalence of $M$ bovoculi in cattle eyes seems quite high in both clinical and nonclinical animals. One study mentioned earlier demonstrated that in a group of calves followed from 1 week to 15 months of age without clinical ocular disease, $M$ bovoculi recovery rate by culture was initially low but increased over time with an overall prevalence of $45 \%$ in normal eyes. ${ }^{13}$ Using a recently developed real-time PCR approach to detect IBK-associated pathogens, Zheng and colleagues found very high prevalence of $M$ bovoculi in case submissions to a diagnostic laboratory (159/179; 88\%). Although diagnostic submissions represent a biased sample, these results indicate that $M$ bovoculi may be an underdetected component of IBK, and PCR testing may reveal it is present at high levels in diagnostic submissions and during outbreaks. ${ }^{30}$ 


\section{Mycoplasma bovis}

M bovis causes a wide array of significant bovine diseases that include pneumonia, mastitis, arthritis, otitis, and keratoconjunctivitis. ${ }^{31}$ It possesses a variety of virulence factors involved in adherence, antigenic variation, host cell invasion, immune modulation, and biofilm formation. ${ }^{31} \mathrm{M}$ bovis has been shown to suppress host immunity via altered cytokine (interferon gamma and tumor necrosis factor alpha) expression, depressed oxidative burst from neutrophils, and suppressed lymphocyte proliferation. ${ }^{31}$ In a retrospective study from a diagnostic reference laboratory in the United Kingdom, $M$ bovis was the most frequently isolated Mycoplasma sp from bovine cases annually, representing $52 \%$ of all Mycoplasmas isolated from cattle over a 10-year period, which were primarily cultured from the lung or upper respiratory tract but also from eyes with IBK lesions..$^{32} \mathrm{M}$ bovis was investigated as a cause in an outbreak of IBK in a beef herd that subsequently developed pneumonia and arthritis. ${ }^{33} \mathrm{M}$ bovis isolates were recovered during the outbreak investigation. All were identified as a single strain that had similarity to other European M bovis strains and possessed variable membrane surface lipoprotein ( $v s p$ ) genes found in $M$ bovis but not in other Mycoplasma spp. ${ }^{34} \mathrm{M}$ bovis has been reported in outbreaks of IBK in 1-year-old beef calves and a group of Holstein cattle in the absence of other pathogens. ${ }^{35,36} \mathrm{M}$ bovis has also been found in mixed Mycoplasma outbreaks of IBK (along with M bovoculi) in Holstein calves following morbidity with respiratory disease that had 30/40 affected. ${ }^{37}$

\section{Other Mycoplasmas}

Other Mycoplasmas, including Mycoplasma bovirhinis and Mycoplasma bovigenitalium in a mixed infection with bovine herpesvirus-1 (BoHV1), have been reported associated with IBK. The significance of these findings is unknown because the role of the individual agents was not evaluated and the findings stem from a series of case reports. ${ }^{38}$ Experimental inoculation of calves with Mycoplasma conjunctivae or Acholeplasma laidlawii did not result in IBK. ${ }^{39}$ 


\section{Ureaplasma}

Ureaplasma, originally classified as T-strain Mycoplasmas, are small pleomorphic bacteria that lack a cell wall and are very similar to Mycoplasma, with the exception of a requirement for urea for growth. ${ }^{33}$ Similar to Mycoplasma, all of the members of the genus are obligate commensals or opportunistic pathogens of vertebrate hosts, primarily of mucosal surfaces. There are 7 species of Ureaplasma, and the species associated with bovine hosts is $U$ diversum, of which there are 3 distinct serologic clusters. ${ }^{40}$ Infections with Ureaplasma spp in cattle are typically associated with reproductive infections or fetal/neonatal pneumonia. ${ }^{41}$ However, there have been some reports of Ureaplasmaassociated ocular infections. Large colony and T-strain mycoplasmas (Ureaplasmas) have been isolated from ocular secretions, along with $M$ bovis in cases of calves with IBK, but not in healthy calves; however, these results are from a single publication 50 years ago and have not been reproduced. ${ }^{42}$ Case reports suggest fetal infections with Ureaplasma spp can induce extensive nonsuppurative conjunctivitis and goblet cell metaplasia throughout the eyelid epithelium. ${ }^{43} \mathrm{M}$ bovoculi and Ureaplasma sp have been recovered from outbreaks of epizootic conjunctivitis. ${ }^{44}$ Inoculation of calves with Ureaplasma spp caused diffuse conjunctivitis and lacrimation, and organisms were able to be recovered from inoculated eyes up to 2 months postinfection. ${ }^{18}$ Overall, the evidence for the role of Ureaplasma spp in IBK is limited at present to a few older studies, and its contribution to the disease complex is likely minor.

\section{Herpesviruses}

Infections with BoHV-1, the causative agent of infectious bovine rhinotracheitis (IBR) can cause ocular disease that resembles IBK. Outbreaks of IBK-like diseases, some with an absence of corneal ulcers, had virus isolated from nasal and ocular secretions. ${ }^{45-50}$ The virus isolated from early outbreaks was determined to be a herpesvirus indistinguishable from that causing IBR. In experimental infections, BoHV-1 produced conjunctivitis but not keratitis in challenged calves, thus indicating 
infection with this herpesvirus caused a disease distinct from IBK. ${ }^{51,52}$ However, BoHV-1 has shown some association with IBK. Challenge with BoHV-1 alone in more recent studies caused conjunctivitis and blepharitis but not keratitis. ${ }^{53}$ Pugh described higher prevalence of IBK in animals that were exposed to BoHV-1 before challenge with $M$ bovis versus those that were exposed to BoHV-1 after $M$ bovis challenge. ${ }^{53}$ George and colleagues demonstrated that vaccination with a modified live IBR vaccine either intranasally or intraocularly increased lesion scores and isolation rates of $M$ bovis in calves challenged with $M$ bovis when compared with nonvaccinated, but challenged, controls. 54 A high seroprevalence (60.1\%) to BoHV-1 was detected in a yak (Poephagus grunniens) farm experiencing an outbreak of abortion and keratoconjunctivitis; no animals had previously been vaccinated against BoHV-1. ${ }^{55}$ However, more recent work looking at an outbreak of IBK in a beef herd did not show an association between BoHV-1 status and IBK. ${ }^{56} \mathrm{~A}$ potential mechanism to explain the association of IBR with IBK is that BoHV-1 causes immune depression characterized by inhibition of polymorphonuclear cell migration and cell-mediated cytotoxicity, which could predispose the host to superinfection with bacterial pathogens. ${ }^{57}$ BoHV-1 also produces host immunosuppression by inhibiting the production of interferon beta, which may also result in secondary infections in the host. ${ }^{58}$

Other alphaherpesviruses have been associated or experimentally shown to cause infectious keratoconjunctivitis-like lesions in a variety of other ruminant species, including mule deer and semidomesticated reindeer and seem to be the primary cause of these lesions in some of these cases. ${ }^{59-63}$

\section{Malignant Catarrhal Fever}

Malignant catarrhal fever (MCF) is caused by 1 of $2 \gamma$-herpesviruses: alcelaphine herpesvirus 1 found in wildebeest and ovine herpesvirus 2 found in sheep, both of which can cause MCF in cattle, bison, deer, pigs, and other ungulates. ${ }^{64-66}$ The reservoir hosts are inapparent carriers, but susceptible species show fever, depression, ocular and nasal discharge, diarrhea, and frequently do not survive. Cattle become infected through direct contact with a host or through aerosol exposure. ${ }^{67}$ Cattle are considered dead-end hosts that do not transmit the 
virus to herdmates. ${ }^{68}$ Although variable in clinical presentation, a common ocular lesion in MCF cases is corneal edema, which may mimic IBK, although cattle with MCF are systemically sick, which is typically not observed in IBK. Other hallmarks of the disease that preclude IBK include the pattern of ocular opacity, with a fine line that spreads centripetally from the limbus, and the presence of concurrent signs such as persistent high fever, salivation, purulent nasal discharge, and generalized lymph node enlargement. ${ }^{69}$ One study of chronic and recovered cattle infected with sheep-associated MCF observed the most obvious clinical sign was bilateral ocular lesions. ${ }^{70}$ Severity of corneal edema at the time of diagnosis is not correlated with clinical outcome in cases of MCF; however, cases of MCF that did not survive had no improvement of corneal edema during hospitalization and treatment in a prospective study. ${ }^{71}$ Other common clinical signs shared with IBK are blepharospasm, ocular discharge, corneal vascularization, conjunctival hyperemia, and miosis. Corneal ulceration, although uncommon in cases of MCF, does occur. ${ }^{71,72}$ Anterior uveitis is a common ocular clinical sign in cases of MCF that is usually absent in cases of IBK. ${ }^{71}$ Histologically, MCF ocular lesions are characterized by mitotic figures in lymphoblasts, which is not a finding in IBK lesions. ${ }^{72}$

\section{Listeria monocytogenes}

L monocytogenes can cause ocular infections that may resemble IBK, which is characterized by keratoconjunctivitis and uveitis, frequently called "silage eye." ${ }^{73,74}$ An excellent review with more detail can be found on this condition. ${ }^{74}$ Briefly, Listeria has been shown experimentally to directly penetrate corneal epithelial cells and cause ocular infections, demonstrating that contact of ocular epithelium with concentrated bacteria, potentially through feed, may be a route of entry, thus the common name of silage eye. ${ }^{75,76}$ The ability to infect bovine conjunctiva seems in some strains to be associated with resistance to lysozyme. ${ }^{77}$ Exposure keratitis secondary to facial nerve palsy caused by infection also seems to be involved. ${ }^{78}$ Clinically, ocular infections with $L$ monocytogenes differ from IBK, whereas in the former, the conjunctivitis is nonpurulent, the cornea has minimal changes, and lesions are usually unilateral. ${ }^{79}$ Outbreak descriptions involve slow spread over several weeks with an intraherd prevalence that ranged between 7\% 
and $29 \% .{ }^{79}$ Three out of 170 cases submitted to a diagnostic laboratory were bovine ocular infections with 4 different subtypes isolated. ${ }^{80,81}$ Outbreaks have also been associated with baleage-fed animals. ${ }^{82} \mathrm{~L}$ monocytogenes infections in cattle associated with silage may be more complex than initially thought. One study looking at an outbreak of $L$ monocytogenes (which primarily caused reproductive infections) in a large system using genomic analysis demonstrated that 3 distinct strains were isolated from animals and only one strain matched those found in silage sources. ${ }^{83}$

\section{Chlamydia spp}

Chlamydia spp are nonmotile obligate intracellular bacteria with small genomes that can replicate in a wide variety of host cells. ${ }^{84}$ Although the nomenclature of members of this genus has been in flux, there are 10 valid species described, 2 of which infect cattle: Chlamydia pecorum and Chlamydia abortus, which were previously classified as Chlamydia psittaci. ${ }^{85-88}$ Infections with Chlamydia spp in cattle typically involve mucosal cells or penetration of mucosal surfaces to establish systemic infection, and infectious elementary bodies are shed in feces, nasal, ocular, and reproductive exudates. ${ }^{89}$ Diseases in cattle include enteric disease, respiratory disease, polyarthritis-serositis, and sporadic bovine encephalomyelitis. ${ }^{89}$ However, asymptomatic infections seem common with one study finding $61 \%$ prevalence in normal calves. ${ }^{90}$ The age of the calf when exposed in addition to the virulence of the strain seem to have impact on the type and severity of disease observed. ${ }^{91}$

Given the infection of mucosal surfaces, Chlamydia spp have long been associated with conjunctivitis in lambs and reindeer among other species, although the relationship with conjunctivitis in cattle is less clear. ${ }^{92,93}$ However, it is thought that infections in cattle are likely to resemble other species. Calves experimentally inoculated with Chlamydia that resulted in systemic infection and polyarthritis also developed conjunctivitis and subsequent blindness that involved the retina and optic nerve. ${ }^{94}$ One report describes 3 outbreaks of IBK-like disease in cattle, one of which lasted 5 months and had morbidity of $100 \%$ where the only agent detected was Chlamydia sp using PCR. ${ }^{95}$ Seven out of 47 conjunctival biopsy samples collected from Kansas cattle 
with signs consistent with IBK, representing 35 herds, had detectable Chlamydial proteins by enzyme-linked immunosorbent assay. ${ }^{96}$ In a study of ruminants in India, 2 out of 8 cattle with clinical keratoconjunctivitis were positive by PCR for Chlamydia spp ( $C$ abortus and $C$ psittaci) ${ }^{97}$ In another survey, high percentages of both clinical (88\%) and nonclinical (68\%) cattle were found to be positive for $C$ psittaci by PCR in a study conducted in Egypt. ${ }^{98} \mathrm{~A}$ study conducted in India revealed that $3 \%$ of ocular infections in cattle with conjunctivitis showed evidence of Chlamydia inclusions in conjunctival smears..$^{99}$ Other outbreaks have indicated $C$ psittaci detection in association with M bovis. ${ }^{100}$

Much remains unclear about the role of Chlamydia spp in bovine disease in general, including ocular disease. Diagnosis of chlamydial infections is challenging, and there may be underdiagnosis and underreporting of this pathogen in cattle. ${ }^{101}$ However, as methods and technologies advance to detect and sequence these organisms, more is being understood. For example, a specific multilocus sequence type of $C$ pecorum (ST23) is associated with ocular infections in sheep and seems to be widespread in livestock including cattle. ${ }^{102,103}$ Cattle infected with Chlamydia have been reported to have growth reduction; however, they seem to be largely subclinical or nonclincal.88,90,104,105

\section{Summary}

Although IBK has classically been associated with Moraxella organisms, there has been work exploring associations with other pathogenic and opportunistic bacteria and ocular lesions in cattle. Many of these pathogens are extremely challenging to study due to their minimal ability to survive outside of hosts and study in vitro. However, as technological advances progress, tools are becoming available to study them using molecular and next-generation sequencing and other approaches. Additional research needs to be conducted into the association of these challenging microbes, in particular Myco bovoculi, and their association and prevalence in both animals with IBK and normal animals. 


\section{Clinics Care Points}

- Determination of the cause of outbreaks is challenging, especially when they may involve poorly understood or uncommon pathogens or opportunistic infections with commensals.

- Organisms other than Moraxella spp have been implicated as causes of IBK-like clinical disease.

- Mycoplasma spp, Ureaplasma spp, Chlamydia spp, L monocytogenes, BoHV-1, and $\gamma$-herpesviruses can produce ocular lesions in cattle.

- Syndromic PCR panels that include non-Moraxella agents may help rule out some of the less common etiologic agents. ${ }^{30}$

- Advanced technologies including molecular characterization of potential pathogens and metagenomics tools will help elucidate the roles other agents play in IBK.

Disclosure The authors have nothing to disclose.

\section{References}

1. Brown DR, May M, Bradbury JM, et al. Mycoplasma. Bergey's Manual of Systematics of Archaea and Bacteria 2018:1-78.

2. Nicholas R, Ayling R, McAuliffe L. Mycoplasma Diseases of Ruminants. Mycoplasma Diseases of Ruminants 2008:1-239.

3. Nicola I, Cerutti F, Grego E, et al. Characterization of the upper and lower respiratory tract microbiota in Piedmontese calves. Microbiome 2017;5(1):152.

4. Timsit $E$, Workentine $M$, Schryvers $A B$, et al. Evolution of the nasopharyngeal microbiota of beef cattle from weaning to 40 days after arrival at a feedlot. Vet Microbiol 2016;187:75-81.

5. McMullen C, Orsel K, Alexander TW, et al. Evolution of the nasopharyngeal bacterial microbiota of beef calves from spring processing to 40 days after feedlot arrival. Vet Microbiol 2018;225:139-48.

6. Lima SF, Teixeira AGV, Higgins $\mathrm{CH}$, et al. The upper respiratory tract microbiome and its potential role in bovine respiratory disease and otitis media. Scientific Rep 2016;6(1):29050.

7. Cullen JN, Lithio A, Seetharam AS, et al. Microbial community sequencing analysis of the calf eye microbiota and relationship to infectious bovine keratoconjunctivitis. Vet Microbiol 2017;207:267-79.

8. De Rudder C, Arroyo MC, Lebeer S, et al. Dual and Triple Epithelial Coculture Model Systems with Donor-Derived Microbiota and THP-1 macrophages to mimic host-microbe interactions in the human sinonasal cavities. MSPHERE 2020;5(1). e00916-19.

9. Bartenslager AC, Althuge ND, Loy JD, et al. Longitudinal assessment of the 
bovine ocular bacterial community dynamics in calves. Anim Microbiome 2021;3(1):16.

10. Dudek K, Nicholas RAJ, Szacawa E, et al. Mycoplasma bovis infectionsoccurrence, diagnosis and control. Pathogens 2020;9(8).

11. Langford EV, Leach RH. Characterization of a mycoplasma isolated from infectious bovine keratoconjunctivitis: M. bovoculi sp. nov. Can J Microbiol 1973; 19(11):1435-44.

12. Langford EV, Dorward WJ. A mycoplasma isolated from cattle with infectious bovine keratoconjunctivitis. Can J Comp Med 1969;33(4):275-9.

13. Barber DM, Jones GE, Wood A. Microbial flora of the eyes of cattle. Vet Rec 1986;118(8):204-6.

14. Salih BA, Rosenbusch RF. Attachment of Mycoplasma bovoculi to bovine conjunctival epithelium and lung fibroblasts. Am J Vet Res 1988;49(10):1661-4.

15. Rosenbusch RF. Bovine pinkeye: etiology and pathogenesis. Bovine Pract 1985; 1985(20):150-2.

16. Calcutt MJ, Foecking MF. Complete Genome Sequence of Mycoplasma bovoculi Strain M165/69T (ATCC 29104). Genome announcements 2014;2(1). e00115-00114.

17. Yogev D, Rosengarten R, Watson-McKown R, et al. Molecular basis of Mycoplasma surface antigenic variation: a novel set of divergent genes undergo spontaneous mutation of periodic coding regions and 5 ' regulatory sequences. EMBO J 1991;10(13):4069-79.

18. Rosenbusch RF, Knudtson WU. Bovine mycoplasmal conjunctivitis: experimental reproduction and characterization of the disease. The Cornell veterinarian 1980;70(4):307-20.

19. Nayar PS, Saunders JR. Infectious bovine keratoconjunctivitis I. Experimental production. Can J Comp Med 1975;39(1):22-31.

20. Friis NF, Pedersen KB. Isolation of Mycoplasma bovoculi from cases of infectious bovine keratoconjunctivitis. Acta Vet Scand 1979;20(1):51-9.

21. Rosenbusch RF. Influence of mycoplasma preinfection on the expression of Moraxella bovis pathogenicity. Am J Vet Res 1983;44(9):1621-4.

22. Rosenbusch RF, Ostle AG. Mycoplasma bovoculi infection increases ocular colonization by Moraxella ovis in calves. Am J Vet Res 1986;47(6):1214-6.

23. Salih BA, Rosenbusch RF. Antibody response in calves experimentally or naturally exposed to Mycoplasma bovoculi. Vet Microbiol 1986;11(1-2):93-102.

24. Salih BA, Ostle AG, Rosenbusch RF. Vaccination of cattle with Mycoplasma bovoculi antigens: evidence for field immunity. Comp Immunol Microbiol Infect Dis 1987;10(2):109-16.

25. Salih BA, Rosenbusch RF. Identification and localization of a 94 kDa membrane protein found in Mycoplasma bovoculi strains. Comp Immunol Microbiol Infect Dis 1998;21(4):281-90.

26. Salih BA, Rosenbusch RF. Cross-reactive proteins among eight bovine 
mycoplasmas detected by monoclonal antibodies. Comp Immunol Microbiol Infect Dis 2001;24(2):103-11.

27. Norian LA, Rosenbusch RF. Mycoplasma bovoculi-augmented bovine natural killer activity. Comp Immunol Microbiol Infect Dis 1993;16(2):113-22.

28. Bansal VK, Garg DN, Singh Y. Seroprevalence of Mycoplasma bovoculi antibodies by ELISA in conjunctivitis affected and healthy bovines. Haryana Veterinarian 2002;41:33-7.

29. Schnee $C$, Heller M, Schubert $E$, et al. Point prevalence of infection with Mycoplasma bovoculi and Moraxella spp. in cattle at different stages of infectious bovine keratoconjunctivitis. Vet J 2015;203(1):92-6.

30. Zheng W, Porter E, Noll L, et al. A multiplex real-time PCR assay for the detection and differentiation of five bovine pinkeye pathogens. J Microbiol Methods 2019; 160:87-92.

31. Burki S, Frey J, Pilo P. Virulence, persistence and dissemination of Mycoplasma bovis. Vet Microbiol 2015;179(1-2):15-22.

32. Ayling RD, Bashiruddin SE, Nicholas RAJ. Mycoplasma species and related organisms isolated from ruminants in Britain between 1990 and 2000. Vet Rec 2004;155(14):413-6.

33. Dando SJ, Sweeney EL, Knox CL. Ureaplasma. Bergey's Manual of Systematics of Archaea and Bacteria 2019:1-28.

34. Alberti A, Addis MF, Chessa B, et al. Molecular and antigenic characterization of a mycoplasma bovis strain causing an outbreak of infectious keratoconjunctivitis. J Vet Diagn Invest 2006;18(1):41-51.

35. Jack EJ, Moring J, Boughton E. Isolation of Mycoplasma bovis from an outbreak of infectious bovine kerato conjunctivitis. Vet Rec 1977;101(14):287.

36. Kirby FD, Nicholas RA. Isolation of Mycoplasma bovis from bullocks' eyes. Vet Rec 1996;138(22):552.

37. Levisohn S, Garazi S, Gerchman I, et al. Diagnosis of a mixed mycoplasma infection associated with a severe outbreak of bovine pinkeye in young calves. J Vet Diagn Invest 2004;16(6):579-81.

38. Naglic T, Sankovic F, Madic J, et al. Mycoplasmas associated with bovine conjunctivitis and keratoconjunctivitis. Acta Vet Hung 1996;44(1):21-4.

39. Pugh GW, Hughes DE, Schulz VD. Infectious bovine keratoconjunctivitis: experimental induction of infection in calves with mycoplasmas and Moraxella bovis. Am J Vet Res 1976;37(5):493-5.

40. Howard CJ, Gourlay RN. Proposal for a Second Species Within the Genus Ureaplasma, Ureaplasma diversum sp. nov. Int J Syst Evol Microbiol 1982;32(4): 446-52.

41. Ross RF. Mycoplasma - Animal Pathogens. In: Kahane I, Adoni A, editors. Rapid diagnosis of mycoplasmas. Boston,: Springer US; 1993. p. 69-109.

42. Gourlay RN, Thomas LH. The isolation of large colony and T-strain mycoplasmas from cases of bovine kerato-conjunctivitis. Vet Rec 1969;84(16):416-7.

43. Crane MB, Hughes CA. Can Ureaplasma diversum be transmitted from donor 
to recipient through the embryo? Two case reports outlining $U$. diversum losses in bovine embryo pregnancies. Can Vet J 2018;59(1):43-6.

44. Truscott RB. Nongenital mycoplasma infections in cattle. Can Vet J 1981;22(11): 335-8.

45. Abinanti FR, Plumer GJ. The isolation of infectious bovine rhinotracheitis virus from cattle affected with conjunctivitis-observations on the experimental infection. Am J Vet Res 1961;22:13-7.

46. Al-Bana AS, Majeed AK, Barhoom S. Isolation of infectious bovine rhinotracheitis virus from calves affected with keratoconjunctivitis. Iraqi J Vet Sci 1998;11(2): 227-31.

47. Bartha A, Magdalena J, Liebermann $\mathrm{H}$, et al. Isolation and properties of a bovine herpes virus from a calf with respiratory disease and keratoconjunctivitis. Arch Exp Veterinarmed 1967;21(2):615-23.

48. Hughes JP, Olander HJ, Wada M. Keratoconjunctivitis associated with infectious bovine rhinotracheitis. J Am Vet Med Assoc 1964;145:32-9.

49. Sykes JA, Dmochowski L, Grey CE, et al. Isolation of a virus from infectious bovine kerato-conjunctivitis. Proc Soc Exp Biol Med Soc Exp Biol Med 1962; 111:51-7.

50. St G TD. Keratoconjunctivitis associated with infectious bovine rhinotracheitis infection in Victorian cattle. Aust Vet J 1965;41:222-3.

51. Mohanty SB, Lillie MG. Relationship of infectious bovine keratoconjunctivitis virus to the virus of infectious bovine rhinotracheitis. The Cornell veterinarian 1970;60(1):3-9.

52. Schulze $\mathrm{P}$, Liebermann $\mathrm{H}$, Hantschel $\mathrm{H}$, et al. Light and electron microscopical examinations of a new bovine herpes virus. Russ Engl Sum Arch Exp Veterinarmed 1967;21(3):747-59.

53. Pugh GW Jr, Hughes DE, Packer RA. Bovine infectious keratoconjunctivitis: interactions of Moraxella bovis and infectious bovine rhinotracheitis virus. Am J Vet Res 1970;31(4):653-62.

54. George LW, Ardans A, Mihalyi J, et al. Enhancement of infectious bovine keratoconjunctivitis by modified-live infectious bovine rhinotracheitis virus vaccine. Am J Vet Res 1988;49(11):1800-6.

55. Nandi S, Kumar M. Serological evidence of bovine herpesvirus-1 (BoHV-1) infection in yaks (Peophagus grunniens) from the National Research Centre on Yak, India. Trop Anim Health Prod 2010;42(6):1041-2.

56. Zbrun MV, Zielinski GC, Piscitelli HC, et al. Dynamics of Moraxella bovis infection and humoral immune response to bovine herpes virus type 1 during a natural outbreak of infectious bovine keratoconjunctivitis in beef calves. J Vet Sci 2011;12(4):347-52.

57. Wyler R, Engels M, Schwyzer M. Infectious Bovine Rhinotracheitis/ Vulvovaginitis (BHV1). In: Wittmann G, editor. Herpesvirus diseases of cattle, horses, and pigs. Boston: Springer US; 1989. p. 1-72.

58. da Silva LF, Sinani D, Jones C. ICP27 protein encoded by bovine herpesvirus 
type 1 (bICP27) interferes with promoter activity of the bovine genes encoding beta interferon 1 (IFN-b1) and IFN-b3. Virus Res 2012;169(1):162-8.

59. Tryland M, Romano JS, Marcin N, et al. Cervid herpesvirus 2 and not Moraxella bovoculi caused keratoconjunctivitis in experimentally inoculated semidomesticated Eurasian tundra reindeer. Acta veterinaria Scand 2017;59(1):23.

60. Muñoz Gutiérrez JF, Sondgeroth KS, Williams ES, et al. Infectious keratoconjunctivitis in free-ranging mule deer in Wyoming: a retrospective study and identification of a novel alphaherpesvirus. J Vet Diagn Invest 2018;30(5):663-70.

61. Sánchez Romano J, Mørk T, Laaksonen S, et al. Infectious keratoconjunctivitis in semi-domesticated Eurasian tundra reindeer (Rangifer tarandus tarandus): microbiological study of clinically affected and unaffected animals with special reference to cervid herpesvirus 2. BMC Vet Res 2018;14(1):15.

62. Tryland M, Das Neves CG, Sunde M, et al. Cervid Herpesvirus 2, the primary agent in an outbreak of infectious keratoconjunctivitis in semidomesticated reindeer. J Clin Microbiol 2009;47(11):3707-13.

63. Sánchez Romano J, Sørensen KK, Larsen AK, et al. Ocular Histopathological Findings in Semi-Domesticated Eurasian Tundra Reindeer (Rangifer tarandus tarandus) with Infectious Keratoconjunctivitis after Experimental Inoculation with Cervid Herpesvirus 2. Viruses 2020;12(9):1007.

64. Loken $\mathrm{T}$, Aleksandersen $\mathrm{M}$, Reid $\mathrm{H}$, et al. Malignant catarrhal fever caused by ovine herpesvirus-2 in pigs in Norway. Vet Rec 1998;143(17):464-7.

65. Reid HW, Buxton D, Berrie E, et al. Malignant catarrhal fever. Vet Rec 1984; 114(24):581-3.

66. Schultheiss PC, Collins JK, Spraker TR, et al. Epizootic malignant catarrhal fever in three bison herds: differences from cattle and association with ovine herpesvirus- 2. J Vet Diagn Invest 2000;12(6):497-502.

67. Russell GC, Stewart JP, Haig DM. Malignant catarrhal fever: a review. Vet J 2009;179(3):324-35.

68. Mushi EZ, Rurangirwa FR. Malignant catarrhal fever virus shedding by infected cattle. Bull Anim Health Prod Afr 1981;29(1):111-2.

69. Crawford TB, O'Toole D, Li H. Malignant Catarrhal Fever. In: Howard JL, Smith RA, editors. Current veterinary therapy 4: food animal practice. Philadelphia: Saunders; 1999. p. 306-9.

70. O'Toole D, Li H, Miller D, et al. Chronic and recovered cases of sheepassociated malignant catarrhal fever in cattle. Vet Rec 1997;140(20):519.

71. Zemljic T, Pot SA, Haessig M, et al. Clinical ocular findings in cows with malignant catarrhal fever: ocular disease progression and outcome in 25 cases (2007-2010). Vet Ophthalmol 2012;15(1):46-52.

72. Whiteley HE, Young S, Liggitt HD, et al. Ocular lesions of bovine malignant catarrhal fever. Vet Pathol 1985;22(3):219-25.

73. Kummeneje K, Mikkelsen T. Isolation of Listeria monocytogenes type 04 from 
cases of keratoconjunctivitis in cattle and sheep. Nord Vet Med 1975;27(3): 144-9.

74. Erdogan HM. Listerial Keratoconjunctivitis and Uveitis (Silage Eye). Vet Clin North Am Food Anim Pract 2010;26(3):505-10.

75. Racz P, Tenner K, Szivessy K. Electron microscopic studies in experimental keratoconjunctivitis listeriosa. I. Penetration of Listeria monocytogenes into corneal epithelial cells. Acta Microbiol Acad Sci Hung 1970;17(3):221-36.

76. Stams A. [Studies in cases of experimental eye infections with Listeria monocytogenes]. Albrecht Von Graefes Arch Klin Exp Ophthalmol 1967;173(1):1-20.

77. Warren J, Owen AR, Glanvill A, et al. A new bovine conjunctiva model shows that Listeria monocytogenes invasion is associated with lysozyme resistance. Vet Microbiol 2015;179(1):76-81.

78. Rebhun WC, deLahunta A. Diagnosis and treatment of bovine listeriosis. J Am Vet Med Assoc 1982;180(4):395-8.

79. Morgan JH. Infectious keratoconjunctivitis in cattle associated with Listeria monocytocytogenes. Vet Rec 1977;100(6):113-4.

80. Evans K, Smith M, McDonough P, et al. Eye Infections due to Listeria Monocytogenes in Three Cows and One Horse. J Vet Diagn Invest 2004;16(5):464-9.

81. Low JC, Donachie W. A review of Listeria monocytogenes and listeriosis. Vet J 1997;153(1):9-29.

82. Laven RA, Lawrence KR. An outbreak of iritis and uveitis in dairy cattle at pasture associated with the supplementary feeding of baleage. New Zealand Vet J 2006;54(3):151-2.

83. Whitman KJ, Bono JL, Clawson ML, et al. Genomic-based identification of environmental and clinical Listeria monocytogenes strains associated with an abortion outbreak in beef heifers. BMC Vet Res 2020;16(1):70.

84. Horn M. Chlamydiae. Bergey's Manual of Systematics of Archaea and Bacteria 2015:1-2.

85. Sachse K, Bavoil PM, Kaltenboeck B, et al. Emendation of the family Chlamydiaceae: proposal of a single genus, Chlamydia, to include all currently recognized species. Syst Appl Microbiol 2015;38(2):99-103.

86. Fukushi H, Hirai K. Proposal of Chlamydia pecorum sp. nov. for Chlamydia strains derived from ruminants. Int J Syst Bacteriol 1992;42(2):306-8.

87. Parte AC, Sardà Carbasse J, Meier-Kolthoff JP, et al. List of Prokaryotic names with Standing in Nomenclature (LPSN) moves to the DSMZ. Int J Syst Evol Microbiol 2020;70(11):5607-12.

88. Poudel A, Elsasser TH, Rahman Kh S, et al. Asymptomatic endemic Chlamydia pecorum infections reduce growth rates in calves by up to 48 percent. PLoS One 2012;7(9):e44961.

89. Perez-Martinez JA, Storz J. Chamydial infections in cattle- Part 1. Mod Vet Pract 1985;66(8):517-22. 
90. Jee J, Degraves FJ, Kim T, et al. High prevalence of natural Chlamydophila species infection in calves. J Clin Microbiol 2004;42(12):5664-72.

91. Storz J, Eugster AK, Altera KP, et al. Behavior of different bovine chlamydial agents in newborn calves. J Comp Pathol 1971;81(2):299-307.

92. Hopkins JB, Stephenson EH, Storz J, et al. Conjunctivitis associated with chlamydial polyarthritis in lambs. J Am Vet Med Assoc 1973;163(10):1157-60.

93. Romano JS, Leijon M, Hagstrom A, et al. Chlamydia pecorum associated with an outbreak of infectious keratoconjunctivitis in semi-domesticated reindeer in Sweden. Front In Vet Sci 2019;6:14.

94. Storz J. Overview of Animal Diseases Induced by Chlamydial Infections. In: Barron A, editor. Microbiology of Chlamydia, vol. 1. Boca Raton: CRC Press; 1988. p. 264.

95. Otter A, Twomey DF, Rowe NS, et al. Suspected chlamydial keratoconjunctivitis in British cattle. Vet Rec 2003;152(25):787-8.

96. Daniels EK, Cole DE. Chlamydial proteins found in bovine conjunctival biopsies. Bovine Pract 1991;(26):142.

97. Gupta S, Chahota R, Bhardwaj B, et al. Identification of chlamydiae and mycoplasma species in ruminants with ocular infections. Lett Appl Microbiol 2015; 60(2):135-9.

98. Osman KM, Ali HA, ElJakee JA, et al. Prevalence of chlamydophila psittaci infections in the eyes of cattle, buffaloes, sheep and goats in contact with a human population. Transboundary Emerging Dis 2013;60(3):245-51.

99. Samantaray SS, Das PK, Das RK, et al. Cytological and microbiological evaluation of conjunctivitis in cattle. Indian J Vet Med 1995;15(2):79-83.

100. Batta MK, Sharma M, Joshi VB, et al. Infectious bovine keratoconjunctivitis in a dairy farm: Etiologic investigations. Indian Vet J 1996;73(7):713-7.

101. Walker E, Lee EJ, Timms P, et al. Chlamydia pecorum infections in sheep and cattle: A common and under-recognised infectious disease with significant impact on animal health. Vet J 2015;206(3):252-60.

102. Jelocnik M, Frentiu FD, Timms $P$, et al. Multilocus Sequence Analysis Provides Insights into Molecular Epidemiology of Chlamydia pecorum Infections in Australian Sheep, Cattle, and Koalas. J Clin Microbiol 2013;51(8):2625.

103. Jelocnik M, Walker E, Pannekoek Y, et al. Evaluation of the relationship between Chlamydia pecorum sequence types and disease using a speciesspecific multi-locus sequence typing scheme (MLST). Vet Microbiol 2014;174(1): 214-22.

104. Reinhold P, Sachse K, Kaltenboeck B. Chlamydiaceae in cattle: Commensals, trigger organisms, or pathogens? Vet J 2011;189(3):257-67.

105. Walker E, Moore C, Shearer $P$, et al. Clinical, diagnostic and pathologic features of presumptive cases of Chlamydia pecorum-associated arthritis in Australian sheep flocks. BMC Vet Res 2016;12:193. 